\title{
Values, ideological attitudes and patriotism
}

\author{
Stefano Livi ${ }^{\mathrm{a}, *}$, Luigi Leone ${ }^{\mathrm{a}}$, Giorgio Falgares ${ }^{\mathrm{b}}$, Francesco Lombardo ${ }^{\mathrm{b}}$ \\ a Department of Social and Developmental Psychology, University of Rome "Sapienza", Via dei Marsi, 78, I-00185 Roma, Italy \\ ${ }^{\mathrm{b}}$ Department of Psychology, University of Palermo, Viale delle Scienze, Ed. 15, I-90128, Palermo, Italy
}

\section{A R T I C L E I N F O}

Article history:

Received 7 October 2013

Received in revised form 18 February 2014

Accepted 22 February 2014

\section{Keywords:}

Values

Authoritarianism

Social Dominance

Blind patriotism

Constructive patriotism

\begin{abstract}
A B S T R A C T
We tested a series of discriminant associations, investigating how dimensions of patriotism (i.e. blind and constructive) differently relate to value orientations, and to ideological attitudes such as Right-Wing Authoritarianism (RWA) and Social Dominance Orientation (SDO). Using an Italian student sample $(N=146)$ we found that blind patriotism correlated positively with tradition and negatively with universalism, whilst constructive patriotism correlated negatively with tradition and positively with universalism. Both RWA and SDO correlated negatively with universalism, whilst only RWA was associated with security and tradition and only SDO related positively to power and self-direction. Mediation analyses revealed that most of the effects of value orientations on patriotism were mediated by SDO and RWA.
\end{abstract}

(c) 2014 Elsevier Ltd. All rights reserved.

\section{Introduction}

Several studies have investigated the relationship between Social Dominance Orientation (SDO), Right-Wing Authoritarianism (RWA) and values (Duriez, Van Hiel, \& Kossowska, 2005; Mc Farland, 2010); the associations among patriotism and values have also been assessed (Schwartz, Caprara, \& Vecchione, 2010); nonetheless, there has been no simultaneous observation of the value associates of RWA, SDO, and patriotism. In particular, no investigation has simultaneously linked SDO, RWA and value dimensions with two distinct forms of patriotism, blind and constructive (Schatz, Staub, \& Lavine, 1999). We hypothesize that values, ideological dimensions and patriotism represent different levels of conceptual generality/specificity: patriotism represents a specific set of attitudes, values represent a much broader set of evaluative dimensions, while SDO and RWA represent socio-ideological dimensions in an intermediate level in the generality/specificity continuum. Hence, we will model the associations among the three conceptual layers of variables as a meditational process, where the effects of value dimensions on patriotism are mediated by the more proximal ideological dimensions of SDO and RWA. Furthermore, we expect to find discriminant associations among blind and constructive patriotism, SDO, RWA and value dimensions. Such association would ascertain

\footnotetext{
* Corresponding author. Address: Department of Social and Developmental Psychology, University of Rome "Sapienza", Via dei Marsi, 78, I-00185 Roma, Italy. Tel.: +39 4991 7967; fax: +39 49917652.

E-mail address: stefano.livi@uniroma1.it (S. Livi).
}

discriminant validity of the two forms of patriotism, linking them differently to ideological and value dimensions.

\subsection{Socio-psychological roots of nationalism and patriotism}

A theoretical distinction can be drawn between nationalism and patriotism, two constructs that are often fuzzily defined, confused or overlapped. Adorno and colleagues (1950) studying the process of individual/group attachment, defined 'genuine patriotism'- in a characteristically evaluative fashion - as "love of country, [...] attachment to national values based on critical understanding" and defined 'pseudopatriotism' as "blind attachment to certain national culture values, uncritical conformity with the prevailing group modalities and rejection of other nations as 'outgroup"' (p. 107). Nationalism is based on an ideology that envisions other countries from a comparative perspective and is dominated by the desire to demonstrate the superiority of one's own, more akin - in Adorno and colleagues' terms, to pseudo-patriotism.

More recently, Schatz, Staub, and Lavine (1999) have distinguished 'blind patriotism' from 'constructive patriotism'. Blind patriotism is defined as "an intense alignment by people with their nation or group and uncritical acceptance and support for its policies and practices, with an absence of moral consideration of their consequences or disregard of their impact on the welfare of human beings who are outside the group or are members of its subgroups" (Staub, 1997, p. 213). Constructive patriotism instead reflects "attachment to and consideration for the well-being of one's own group with an inclusive orientation to human beings, with respect for the rights and welfare of all people" (Staub, 1997, p. 214). 
Both positions could be deemed 'patriotic' to the extent that they reflect a sense of emotional attachment to the Nation. Like constructive patriots, blind patriots are loyal to and proud of their country, but they do not judge invariably the actions of their nation as right or necessary. Blind patriotism overlaps with nationalistic attitudes and requires a submissive attitude to the nation and its leaders; criticism and dissent are generally regarded as signs of unwarranted rebellion and disloyalty, even treason to the Homeland. Conversely, constructive patriotism is a form of behavioural attachment to the Nation based on flexibility, aptitude and willingness to reflect and act with regard to the welfare of one's own country.

These two forms of patriotism may be differently related to value dimensions and to ideological dimensions. Right-wing and conservative ideological dimensions can be related in particular to blind forms of patriotism (Pena \& Sidanius, 2002; Jugert \& Duckitt, 2009). Recent conceptualizations of the ideological roots of conservatism focus on a two-dimensional approach to socio-political ideologies pivoted on the constructs of Right-Wing Authoritarianism (RWA) and Social Dominance Orientation (SDO). According to Altemeyer (1996), RWA refers to an 'authoritarian follower' with a disposition towards discipline and punishment (i.e. aggression), respect for authority (i.e. submission) and adherence to conventional values (i.e. conventionalism). RWA has been linked to heightened concern about power, security, conformity and tradition, such that the higher the RWA score, the more punitive and easily influenced by authority directives an individual tends to be (Altemeyer, 1981). Social Dominance Orientation reflects the tendency of certain individuals to subject others to their own antidemocratic authoritarianism (Sidanius \& Pratto, 1999). High-SDO individuals develop and support so-called hierarchy-enhancing legitimizing myths (HELMs), or societal, consensually shared social ideologies, that provide moral and intellectual justification for practices that asymmetrically allocate social values among social groups (Pratto, Sidanius, Stallworth, \& Malle, 1994; Sidanius \& Pratto, 1999). Research has shown that SDO correlates strongly with prejudice, racism, sexism, cultural elitism, political and economic conservatism, meritocracy, a Protestant ethic, 'just-world' beliefs, and nationalism (e.g. Pratto, 1999).

RWA and SDO should be both linked positively with blind patriotism, which is a form of out-group derogation and in-group enhancement that fits well both with the "authoritarian follower" who derogates the out-group because it is always a potential threat to the ingroup. Furthermore, blind patriotism fits also with the social dominant individual, who likes to impose a self-serving hierarchy and allocation of resources to maximize the advantages of one's own group, or Nation for that matter. Instead, constructive patriotism does not feature the same concern on security, threat and hierarchy embedded within blind forms of national attachment. Consistently, blind patriotism has typically been found to be strongly correlated with RWA; instead, constructive patriotism has been found to be unrelated to RWA (Schatz et al., 1999; Spry \& Hornsey, 2007). Pratto and colleagues (1994) found that patriotism (which was measured in a way more reminiscent of its blind version) increased as a function of SDO among white Americans, the dominant group, while it decreased as a function of SDO among African Americans, subordinates, a pattern that represents a special case of the ideological asymmetry hypothesis (Sidanius, Levin, \& Pratto, 1996). These results would imply also an as yet untested negative association between SDO and constructive patriotism.

The results of these studies represent a good starting point for the investigation of SDO and patriotism, as no research to date has explicitly examined SDO and blind or constructive patriotism. We here hypothesize that both RWA and SDO should be associated positively with blind patriotism, reflecting two different motivations (threat and dominance, respectively) underpinning dogmatic favouritism for one's own nation; instead, RWA and SDO should be negatively or negligibly associated with constructive patriotism, because the latter reflects an attachment to one's own country conceptually unrelated with worries about threat-avoidance or hierarchy-enhanced motivations (RWA and SDO, respectively).

\subsection{Values as distant roots of patriotism}

SDO and RWA could act as the ideological mediators between the specific attitudes and beliefs that comprise blind and constructive patriotism and broader dispositional dimensions, as values. Schwartz's Values Inventory (1992), developed to measure values expressing basic human motivational goals, has proved very useful as a conceptual tool for disentangling the distinct antecedents of RWA and SDO. The theory of basic human values developed by Schwartz (1992) distinguishes ten types of motivational value: Universalism, Benevolence, Tradition, Conformity, Security, Power, Achievement, Hedonism, Stimulation, and Self-direction. Because of the inherent compatibilities and conflicts of the motivational goals underlying these value types, they are arranged in the afore-mentioned order in a two-dimensional structure. On one dimension, Self-enhancement values - power, achievement - contrast with Self-transcendence values - universalism, benevolence; and on the other dimension, Conservative values - tradition, conformity, security - contrast with Openness-to-change values hedonism, stimulation, self-direction. The dynamic relationships between values have been confirmed in a large number of societies all over the world, using various samples and different methods of measurement and data analysis (Schwartz, Melech, Lehmann, Burgess, \& Harris, 2001).

SDO and RWA differ in their associations with the value dimensions. Duriez, Van Hiel, and Kossowska (2005) and Mc Farland (2010) related RWA to the conservatism vs. openness-to-change axis, while SDO lies on the self-enhancement vs. self-transcendence axis. Both RWA and SDO correlate with self-enhancement and conservative values, but only RWA is strongly correlated with conservatism (security, conformity, and tradition) vs. openness-tochange - (stimulation and self-direction). In contrast, SDO relates correlated with self-enhancement (achievement, power, and hedonism) vs. self-transcendence (universalism, benevolence). Cohrs, Maes, Moschner, and Kielmann (2007) found that security was positively associated with RWA and SDO, which in turn correlated negatively with universalism. Stangor and Leary (2006) used different measures of motivationally-based values but also found a strong positive correlation between conservative values and RWA, but not SDO, and a negative correlation between egalitarian values and SDO, but not RWA.

Previous research have also investigated the direct associations between values and blind patriotism. Schwartz et al. (2010) reported that blind patriotism correlates positively with security, conformity, tradition and power, because uncritical attachment to, and identification with one's country provides a sense of certainty and superiority. On the other hand, blind patriotism showed negative correlations with universalism, self-direction, stimulation, and hedonism, because blind patriotism is intolerant of outgroups and conflicts with free, individual self-expression.

The aforementioned associations are compatible with a mediation pattern where the proximal associates of patriotism (SDO and RWA) mediate the distinct associations of blind and constructive patriotism with value dimensions. We aim at testing such pattern. For this purpose, we will first test a model focusing on the associations of SDO and RWA with values, in order to compare the results with those previously reported in the literature (see Duriez et al., 2005). We consider values to represent the starting point from which ideological dispositions as RWA and SDO develop. To simplify the model, we decided from a theoretical standpoint to focus 
on the values of power, self-direction, universalism, security and tradition which appear prima facie to be conceptually associated with patriotism and with SDO and RWA, as shown in the literature. Other values as conformity and benevolence could be associated with RWA and SDO (e.g., Altemeyer, 1998; Duriez et al., 2005), but we expect these values to be less pivotal compared with adjacent value dimensions as universalism and tradition. We predicted that power would be conceptually related to a preference for hierarchy and therefore potentially represent a basis for SDO. A similar argument can be made for the relationship with self-direction: we predict it will be positively correlated to SDO, without any necessary correlation with RWA, which is characterized by a marked preference for societal uniformity and a tendency to accord primacy to the community over individual self-determination. Security, an important substrate of RWA and conservatism in general, was not expected to be linked to SDO, a harbinger of change and instability. Finally, traditionalism was predicted to be directly connected to RWA, which generally views tradition as a means of preserving the status quo. Tradition was predicted to be independent of SDO, which is less oriented towards maintenance of the status quo than RWA.

Using the same set of values, a second model will test the relationship between values and the two forms of patriotic attachment to the nation. As previous studies by Schwartz and colleagues (2010) we expect blind patriotism to be linked positively to tradition, and power and negatively with self-direction and universalism due to the fact uncritical attachment to one's country provides a sense of certainty and superiority but also intolerance of outgroups and conflicts with free, individual self-expression. Conversely we do expect positive relations of constructive patriotist due to the consideration for the well-being of one's own group with an inclusive orientation to human beings, such as universalism with respect for the rights and welfare of all people, but also negatively to tradition, for the flexibility to reflect and change for the welfare of the ingroup. Finally, modeling simultaneously the whole set of variables, we hypothesized that the effects of values dimensions on the two patriotisms, as specific attachment to the ingroup, would be mediated by the more proximal socio-ideological dimensions of RWA and SDO.

\section{Method}

\subsection{Participants}

Data for analyses were collected from 146 Italian university students aged $19-40$ years $(M=23.79, \mathrm{SD}=6.654)$. Forty-five participants were males $(30.8 \%)$ and 101 females (69.2\%). The students were attending various faculties (Architecture, Biology, Economics, Law, Engineering, Arts and Humanities, Psychology, Mathematics, Political Sciences).

\subsection{Measures}

The Italian version (Capanna, Vecchione, \& Schwartz, 2005) of the Portrait Values Questionnaire (PVQ) was preferred to the Schwartz Value Survey (SVS) in order to have a less abstract method (Schwartz et al., 2001) that more suited for the specific aim of the study. Moreover, no psychometric validation is actually available for the SVS in Italy. Each of the 40 items of the PVQ provides a brief portrait of a 'person type' describing that person's goals, aspirations or desires. The respondents had to give, for each person described, a rating of the perceived degree of similarity to themselves on a six-point Likert scale (verbal response categories ranged from 'not at all like me' to 'very like me') (all reliabilities $\alpha$ values are reported in Table 1 ).
RWA Scale (Aiello, Chirumbolo, \& Leone, 2004; Altemeyer, 1998): thirty-item scale on which the respondent expresses their degree of agreement with each item using a seven-point scale (Sample item:"Authorities such as parents and our national leaders generally turn out to be right about things, and the radicals and protestors are almost always wrong").

SDO Scale (Italian version; Aiello, Chirumbolo, Leone, \& Pratto, 2005): fifteen-item scale on which the respondent expresses their degree of agreement with each item using a seven-point scale (Sample item:"This country would be better off if we cared less about how equal all people are").

Blind and constructive patriotism scale: sixteen-item scale, reflecting the blind and constructive patriotism constructs (Schatz et al., 1999). Statements are illustrative of blind patriotism e.g. "People who do not wholeheartedly support Italy should live elsewhere" or "I would support my country right or wrong"; or constructive patriotism e.g. "If I criticize Italy, I do so for love of country" or "If you care about Italy, you should notice her problems and work to correct them." Respondents were asked to answer using a six-point Likert scale ranging from 1 ('completely disagree') to 6 ('completely agree').

\section{Results}

Table 1 reports correlations of the value dimensions with patriotism and SDO and RWA scores. RWA was associated negatively with self-direction and universalism, and positively with security conformity and tradition. These three latter values were not associated with SDO, which in turn related to universalism and benevolence (negatively) and power and achievement (positively). Results accord reasonably well with previous results (Altemeyer, 1998; Duriez \& Van Hiel, 2002; Duriez et al., 2005; McFarland, 2005), with the exception of the negative correlation found between RWA and universalism, which emerged only as a trend in one other Italian study (Falgares \& Di Stefano, 2007). Blind patriotism correlated positively with RWA and SDO and negatively with benevolence and universalism, whilst the latter related positively to constructive patriotism, which in turn was negatively related to tradition, RWA and SDO.

\subsection{Values, RWA and SDO}

As stated above, we focused on the values of power, self-direction, universalism, security and tradition. Overall, the five values should provide a fairly comprehensive representation of SDO and RWA. ${ }^{1}$ We hypothesized that RWA was only uniquely influenced by orientation towards security and tradition, whilst SDO is influenced by orientation towards power and self-direction. Universalism was hypothesized to be a common, and negative, associate of both constructs. To test these dissociation hypotheses, we implemented the double regression model in Fig. 1, and found that the fit was satisfactory (c.f. Hu \& Bentler, 1999): $\chi^{2}(36, N=145)=49.79, p=.063$, $R M S E A=.052(90 \% \mathrm{CI}: .00-.084) ; N N F I=.97 ; C F I=.98$. The addition of further paths did not improve fit significantly: $\Delta \chi^{2}(4)=7.39, p>$ .05. Parameter estimates show that RWA and SDO share only (low) universalism as a common substrate, and are clearly discriminated in terms of the other values: RWA is oriented towards security and tradition, SDO towards power and self-direction (Altemeyer, 1998). The pool of values considered affected RWA more strongly than SDO. This is suggested by the differences in regression coefficients that showed the effects of predictors of RWA - universalism ex-

\footnotetext{
${ }^{1}$ Although conformity, achievement and benevolence are also related to RWA or SDO, preliminary analyses showed that these effects are subsumed by the unique effects on RWA and SDO of tradition, power and universalism.
} 
Table 1

Correlation matrix between patriotism, RWA and SDO and reliabilities of the scales.

\begin{tabular}{|c|c|c|c|c|c|}
\hline & RWA & SDO & Blind Patriotism & Constructive patriotism & Reliability coefficient \\
\hline Self-direction & $-38^{* *}$ & .16 & -.15 & .13 & .61 \\
\hline Universalism & $-.35^{* *}$ & $-.46^{* *}$ & $-.34^{* *}$ & $.25^{*}$ & .76 \\
\hline Benevolence & -.16 & $-.29^{* *}$ & $-.24^{* *}$ & .16 & .63 \\
\hline Stimulation & -.14 & .03 & .05 & .08 & .65 \\
\hline Hedonism & .02 & .16 & .13 & -.02 & .69 \\
\hline Achievement & -.11 & $.25^{* *}$ & .09 & -.03 & .78 \\
\hline Power & -.08 & $.36^{* *}$ & .08 & -.15 & .73 \\
\hline Security & $.41^{* *}$ & .04 & .11 & .03 & .70 \\
\hline Conformity & $.35^{* *}$ & -.11 & .11 & -.16 & .54 \\
\hline Tradition & $.36^{* *}$ & -.13 & .13 & $-.24^{* *}$ & .42 \\
\hline RWA & 1 & $21^{*}$ & $49^{* *}$ & $-19^{*}$ & .88 \\
\hline SDO & $21^{*}$ & 1 & $35^{* *}$ & $-27^{* *}$ & .81 \\
\hline Blind patriotism & $49^{* *}$ & $35^{* *}$ & 1 & $-37^{* *}$ & .82 \\
\hline Constructive patriotism & $-.19^{*}$ & $-.27^{* *}$ & $-.37^{* *}$ & 1 & .75 \\
\hline
\end{tabular}

Significance levels: ${ }^{*} p<.05 ;{ }^{* *} p<.01$.

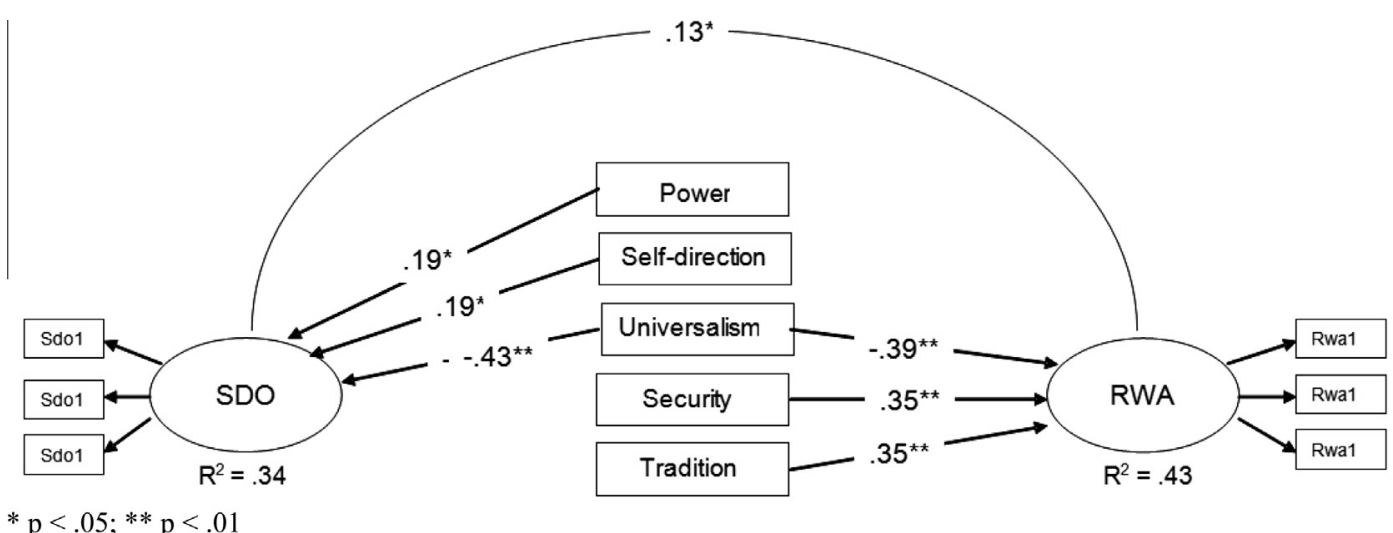

Fig. 1. Dissociated effects of values on SDO and RWA. ${ }^{*} p<.05 ;{ }^{* *} p<.01$.

cluded - to be stronger than the effects of values associated with SDO: $\Delta \chi^{2}(3)=9.23, p<.03$.

\subsection{Values and patriotism}

We investigated patriotism within the same framework and pool of values considered above. A saturated model which considered all the paths from the five values to blind and constructive patriotism revealed only significant effects for universalism and tradition. We simplified the model excluding all but these two paths and obtained a good-fitting model (Fig. 2): $\Delta \chi^{2} 2(6$, $N=145)=5.78, p=.45 ; R M S E A=0.0, N N F I=1.00 ; C F I=1.00$. The effects on blind and constructive patriotisms were opposite: the effect of tradition on blind patriotism was positive $(p<.05$, onetailed), but negative on constructive patriotism; the effect of universalism on blind patriotism was negative, but positive on constructive patriotism. These results suggest that the two patriotisms are dissociated, and that they seem to be favoured or inhibited by different reference values. However, it has to be noted that the explanatory power of the values is quite small, as indicated by the low percentage of variance explained.

\subsection{Direct and indirect effects}

We then tested whether the effects of tradition and universalism on the two patriotisms would be mediated by RWA and

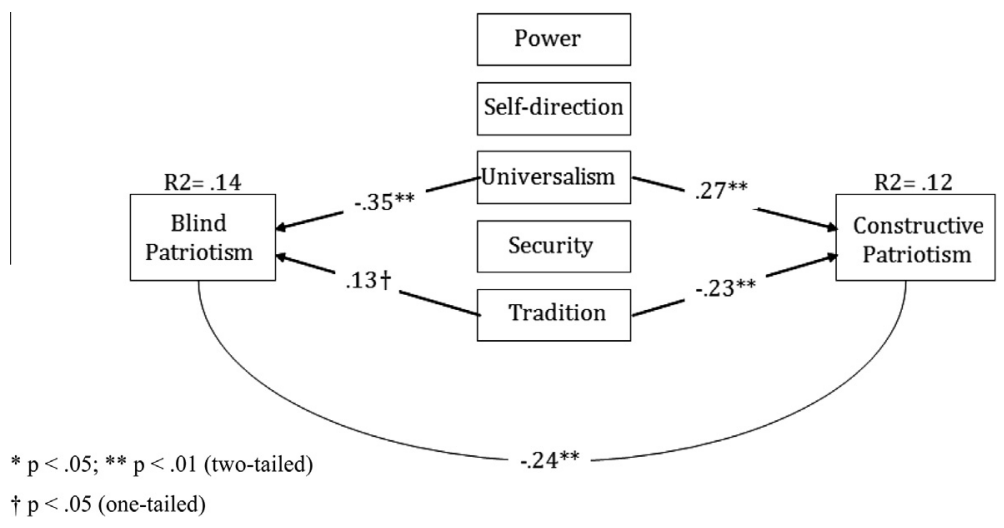

Fig. 2. Patriotism and values. ${ }^{*} p<.05 ;{ }^{* *} p<.01$ (two-tailed); ${ }^{\dagger} p<.05$ (one-tailed). 
SDO; aslo, we expected RWA and SDO to show opposite associations with blind and constructive patriotism. Fig. 3 presents the conceptual model proposed. The model assuming total mediation of the observed effects of tradition and universalism on patriotism did not fit well: $\chi^{2}(54, N=145)=77.69, p=.02 ; R M S E A=.055$ (C.I.: $.023-.081), N N F I=.96 ; C F I=.97$. Although the relative fit indices are compatible with a good-fitting model (Hu \& Bentler, 1999), considering the relatively limited sample size the Chi-squared is a robust index of model misfit (Bollen, 1989). In view of this we reformulated the total mediation hypothesis into a less restrictive partial mediation one, adding the direct effect of tradition on constructive patriotism.

Fig. 4 presents the revised model pointing out that - as with any change in post-hoc specifications of the confirmatory models - the results should be approached with caution and subjected to independent sample replication. The revised model fits well $\left(\chi^{2}(53\right.$, $N=145)=69.06, \quad p=.068 ; \quad R M S E A=.046 \quad$ (C.I.: $.000-.074)$, $N N F I=.97 ; C F I=.98)$ and the significant difference from the total mediation model underscores the importance of the direct effect of tradition on constructive patriotism: $\Delta \chi^{2}(1)=8.63, p<.01$.
The addition of other direct effects of values on patriotisms would not improve the adequacy of the model to the data (all $\Delta \chi^{2}$ $(1)<3.12$, all $p s>.07$ ).

The theoretical predictions proved fairly accurate: opposing effects of RWA and SDO on the two forms of patriotism, with the exception of the non-significant effect of RWA on constructive patriotism. RWA and SDO explained a large portion of the variance in blind patriotism (35\%) but a substantially smaller portion of variance in constructive patriotism (14\%). Thus, while blind patriotism can be considered part of the intergroup relationships dimension (between nations or ethno-national groups) within the authoritarianism constellation, constructive patriotism derives most of its ideological drive from areas external to authoritarian personality.

\section{Discussion}

The proposed models offer a conceptual framework that largely confirms the expectations and more clearly defines the relationship between values, RWA, SDO and the effects that arise with

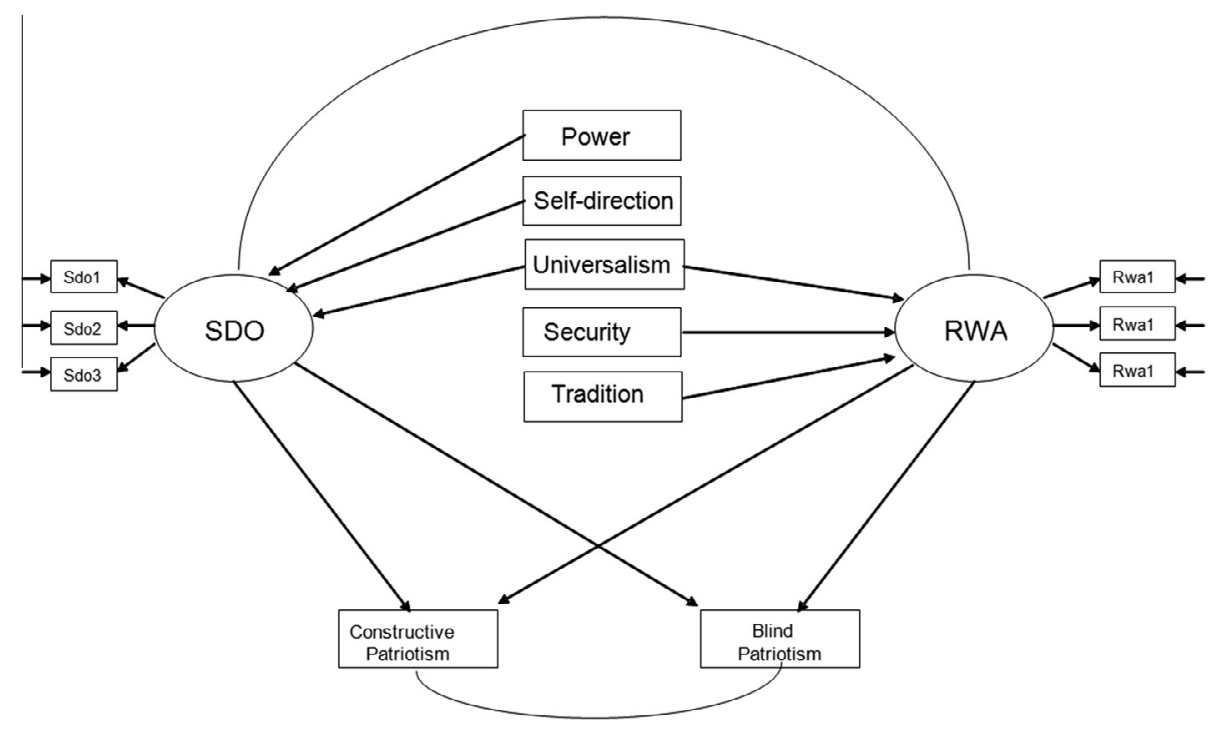

Fig. 3. Full mediational model.

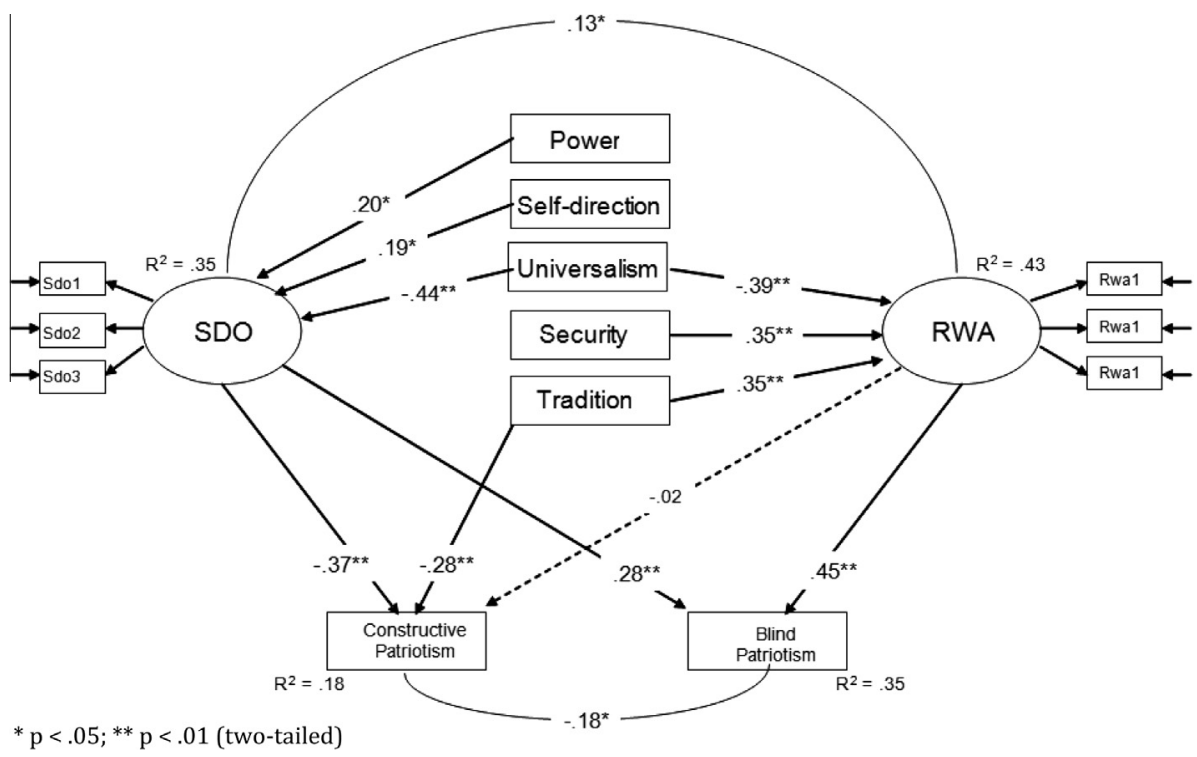

Fig. 4. Partial mediation model. ${ }^{*} p<.05 ;{ }^{* *} p<.01$ (two-tailed). 
the two forms of patriotism. SDO and RWA show the same trend towards rejection of universalism, albeit for different reasons: assertion of diversity for SDO; defence of specificity for RWA. Both ideological attitudes were once considered to be based on common values, specifically the marginal importance accorded to universalism by individuals with a high tendency toward RWA and SDO; but the value profiles of SDO and RWA appear to differ confirming previous studies (Duriez et al., 2005), at least in our Italian student sample: RWA is sensitive to security and tradition, while a highSDO individual seems to be motivated by power and self-direction. Taken together, these results are consistent with the literature asserting the conceptual independence of RWA and SDO (Altemeyer, 1998; Roccato \& Ricolfi, 2005; Duckitt \& Sibley, 2010).

The two forms of patriotism show an opposite relationship with the values of tradition and universalism: blind patriotism repudiates universalist values and affirms traditionalist values (Schwartz et al., 2010), while the opposite is true for constructive patriotism. A deeper analysis, however, shows how these values are empirically mediated by RWA and SDO, specifically with regard to the relationship between RWA and blind patriotism. On the other hand, if blind patriotism is defined as a rigid and inflexible attachment to the state, characterized by a positive evaluation of unquestioned loyalty and frank intolerance of criticism (Schatz et al., 1999), an ideological substrate is needed to legitimize activities and behaviours aimed at maintaining and promoting the existence of the social group. Still more interesting theoretical reasons underlying the relative marginality of the effects of the authoritarian personality on constructive patriotism may be identified. Constructive patriotism, like blind patriotism, encompasses loyalty to country, but its deep-rooted needs - constructive criticism and aspiration towards achieving the profound well-being of the nation and its components - are oriented towards universalism and inalienable human rights, even at the expense of group conformity.

We want to underline that nowadays 'leftist' - or simply 'not right-wing' - ideological constructs are investigated less and less well understood by psychosocial research. As a result, they are sometimes interpreted as the mirror image of 'right-wing' constructs. Indeed, the relationships between constructs often mirror each other in certain respects, but - as in our study - prove weaker. To some extent, the limited explanatory power of SDO and RWA with regard to constructive patriotism must be traced not only to the ideological construct, but to the different orientation of RWA with respect to the predictors (positive) and the criterion (negative). In other words, a sort of common method effect may drive the higher explanatory power observed for blind patriotism compared with the variance explained for constructive patriotism (Podsakoff, MacKenzie, Lee, \& Podsakoff, 2003). A different explanation considers that the processes linking values to liberal orientations are not simply the flip side of the coin, i.e. of the role of values for conservatism (Federico, Deason, \& Fisher, 2012). Future research will be needed to trace back the dispositional origins of relatively more liberal attitudes as non-antagonistic (i.e. constructive) patriotism.

\section{References}

Adorno, T. W., Frenkel-Brunswik, E., Levinson, D. J., \& Sanford, R. N. (1950). The autoritarian personality. New York: Harper.

Aiello, A., Chirumbolo, A., \& Leone, L. (2004). La Scala di Autoritarismo di Destra (Altemeyer, 1998): Uno studio di adattamento e validazione. Rassegna di Psicologia, 21, 73-91.

Aiello, A., Chirumbolo, A., Leone, L., \& Pratto, F. (2005). Uno studio di adattamento e validazione della Scala di orientamento/tendenza alla dominanza sociale. Rassegna di Psicologia, 22, 65-75.
Altemeyer, B. (1981). Right-wing authoritarianism. Winnipeg: University of Manitoba Press.

Altemeyer, B. (1996). The authoritarian specter. Cambridge, MA, USA: Harvard University Press.

Altemeyer, B. (1998). The other authoritarian personality. In M. P. Zanna (Ed.). Advances in experimental social psychology (30, pp. 47-92). San Diego: Accademic Press.

Bollen, K. A. (1989). Structural equations with latent variables. New York: Wiley.

Capanna, C., Vecchione, M., \& Schwartz, S. H. (2005). La misura dei valori. Un contributo alla validazione del Portrait Values Questionnaire su un campione italiano. Bollettino di Psicologia Applicata, 246, 29-41.

Cohrs, J. C., Maes, J., Moschner, B., \& Kielmann, S. (2007). Determinants of human rights attitudes and behavior: A comparison and integration of psychological perspectives. Political Psychology, 28, 441-469.

Duckitt, J., \& Sibley, C. G. (2010). Personality, ideology, prejudice, and politics: A dual-process motivational model. Journal of Personality, 78, 1861-1893.

Duriez, B., \& Van Hiel, A. (2002). The march of modern fascism. A comparison of social dominance orientation and authoritarianism. Personality and Individual Differences, 32, 1199-1213.

Duriez, B., Van Hiel, A., \& Kossowska, M. (2005). Authoritarianism and social dominance in western and eastern Europe: The importance of the sociopolitical context and of political interest and involvement. Political Psychology, 26, 299-320.

Di Stefano, G., \& Falgares, G. (2007). Le relazioni tra autoritarismo di destra orientamento alla dominanza sociale e struttura psicologica universale dei valori di Schwartz. In F. Di Maria, G. Di Stefano, \& G. Falgares (Eds.), Psiche e Società. La polis siciliana tra mondo interno e mondo esterno (pp. 46-62). Milano: Franco Angeli.

Federico, C. M., Deason, G., \& Fisher, E. L. (2012). Ideological asymmetry in the relationship between epistemic motivation and political attitudes. Journal of Personality and Social Psychology, 103, 381-398.

Hu, L. T., \& Bentler, P. M. (1999). Cutoff criteria for fit indexes in covariance structure analysis: Conventional criteria versus new alternatives. Structural Equation Modeling, 6, 1-55.

Jugert, P., \& Duckitt, J. (2009). A motivational model of authoritarianism: Integrating personal and situational determinants. Political Psychology, 30, 693-719.

McFarland, S. G. (2005). On the eve of war: Authoritarianism, social dominance, and American students' support for attacking Iraq. Personality and Social Psychology Bulletin, 31, 360-367.

Mc Farland, S. (2010). Authoritarianism, social dominance, and other roots of generalized prejudice. Political Psychology, 31, 453-477.

Pena, Y., \& Sidanius, J. (2002). U.S. patriotism and ideologies of group dominance: A tale of asymmetry. Journal of Social Psychology, 142, 782-790.

Podsakoff, P. M., MacKenzie, S. B., Lee, J. Y., \& Podsakoff, N. P. (2003). Common method biases in behavioral research: A critical review of the literature and recommended remedies. Journal of Applied Psychology, 88, 879-903.

Pratto, F. (1999). The puzzle of continuing group inequality: Piecing together psychological, social, and cultural forces in social dominance theory. In M. Zanna (Ed.). Advances in experimental social psychology (33, pp. 41-113). San Diego: Academic Press.

Pratto, F., Sidanius, J., Stallworth, L. M., \& Malle, B. F. (1994). Social dominance orientation: A personality variable predicting social and political attitudes. Journal of Personality and Social Psychology, 67, 741-763.

Roccato, M. \& Ricolfi, L. (2005). On the correlation between right-wing authoritarianism and social dominance orientation. Basic \& Applied Social Psychology, 27, 187-200.

Schatz, R. T., Staub, E., \& Lavine, H. (1999). On the varieties of national attachment: Blind versus constructive patriotism. Political Psychology, 20, 151-174.

Schwartz, S. H. (1992). Universals in the content and structure of values: Theoretica advances and empirical tests in 20 countries. Advances in Experimental Social Psychology, 25, 1-65.

Schwartz, S. H., Caprara, G. V., \& Vecchione, M. (2010). Basic personal values, core political values, and voting: A longitudinal study. Political Psychology, 31 421-452.

Schwartz, S. H., Melech, G., Lehmann, A., Burgess, S., \& Harris, M. (2001). Extending the cross-cultural validity of the theory of basic human values with a different method of measurement. Journal of Cross-Cultural Psychology, 32, 519-542.

Sidanius, J., Levin, S., \& Pratto, F. (1996). Consensual social dominance orientation and its correlates within the hierarchical structure of American society. International Journal of Intercultural Relations, 20, 385-408.

Sidanius, J., \& Pratto, F. (1999). Social dominance: An intergroup theory of social hierarchy and oppression. New York: Cambridge University Press.

Spry, C., \& Hornsey, M. (2007). The influence of blind and constructive patriotism on attitudes toward multiculturalism and immigration. Australian Journal of Psychology, 59, 151-158.

Stangor, C., \& Leary, M. (2006). Intergroup beliefs: Investigations from the social side. In M. Zanna (Ed.). Advances in experimental social psychology (33, pp. 41-113). San Diego: Academic Press.

Staub, E. (1997). Blind versus constructive patriotism: Moving from embeddedness in the group to critical loyalty and action. In D. Bar-Tal \& E. Staub (Eds.) Patriotism in the lives of individuals and nations (pp. 213-228). Chicago: Nelson Hall. 